\title{
Pedestrian safety indicators study
}

\author{
S. Amoroso \& L. Caruso \\ Department of Transport Engineering, University of Palermo, Italy
}

\begin{abstract}
Pedestrian mobility can be considered an important feature in a new model of town organization, being suitable for the newly urbanized areas as well as the old quarters and the outskirts, places where streets and squares, once devised for a pedestrian based mobility, were eventually overcame by an ever increasing motorized traffic. Enhancing pedestrian mobility could bring new life and activities into the old and historic parts of the town reviving their original identities. The last decade's increase in the recourse to private cars requires improvements in pedestrian mobility quality. This can be achieved by building new infrastructures, limiting the use of private cars, improving public transport and planning fully accessible parking areas. The planning of new quarters is often performed considering a wide use of private cars, thus resulting in urban highways and long and winding local roads hindering pedestrian mobility and safety. Location and layout of pedestrian crossings are the main issues in safety, requiring a set of indicators to model pedestrian behaviours and to assess route quality and safety. Town social features and mobility purpose, related to pedestrian age, are important elements to define the Pedestrian Safety Indicators. Using a GIS software, an evaluation of risk was carried out along main urban roads in order to study and develop measures to reduce casualties involving pedestrians, taking into account the sidewalk levels of service and other factors that may interfere with pedestrian safety. The aim of this research is to provide useful guidelines to recognize and analyze critical conditions and proper solutions for pedestrian safety in an urban environment.
\end{abstract}

Keywords: pedestrian mobility, pedestrian safety, GIS, level of service, pedestrian safety indicators, sidewalk, pedestrian crossing. 


\section{Introduction}

The intensive use of private cars in urban areas has negatively affected road safety and mobility quality, increasing, at the same time, atmospheric and acoustic pollution. Hence the need for a new modal arrangement of urban transport is strongly felt. In particular, fostering the so called "alternative mobility solutions" like pedestrian mobility, which guarantee low environmental impacts, is generally acknowledged as the goal to pursue. In this perspective, actions aimed to limit, even just partially, the use of private cars, like the creation of pedestrian precincts, can improve significantly the quality and safety of urban transfers, making pedestrian mobility an essential part of an integrated system of different transport modes. Some pedestrian route features influence the quality of the public transit offer, affecting the general cost of transport. The intermodality between pedestrian mobility and public transit mobility plays a key role in the improvement of urban transfer sustainability. Making walking in town a real and practical transfer option aims to redesign, to the extent feasible, the layout of urban areas, which are now too much affected by an ever increasing motorized traffic. The problem set by the previous considerations is to determine which of the transport offer parameters can influence the modal choice towards pedestrian mobility. It's certain that people are sensitive to travel times rather than to travel distances. Transits are to be made during a time interval that allows destinations to be reached within a settled time. Pedestrians need to know in advance which factors will influence their travel times and eventually cause delays, like for example waiting at crossings. When pedestrians perceive to be late, they change their behaviour. An increase in walking speed is generally associated with a less proper behaviour, with the sole purpose of arriving in time. Pedestrians who are late tend to neglect some basic safety rules, this typically results in walking on carriageways, when sidewalks are crowded, or crossing the road outside zebra crossings, facing a high risk of being run over by vehicles in transit. Among the factors that can shift the transit modal choice towards walking, are the conditions of sidewalks, and the attractiveness and quality of public transit terminals, such as stations and bus stops. In order to take into account the whole of this factors we have been developing a method to try to fill the gap between pedestrian mobility and the other modes of urban transport, by making walking in town safer and more enjoyable.

\section{Literature review}

Transport engineering literature on the topic mostly refers to the concept of "level of service" (LOS) of a particular area [1]. Specifically chapter 18 of the Highway Capacity Manual describes a method to analyze the capacity and level of service of pedestrian infrastructures. The method evaluates the effects that traffic signalling and pedestrian flows have on pedestrian infrastructures, through the analysis of their level of service. Some authors have also introduced an indicator that takes into account the sidewalk conditions [2]. Low walking comfort often depends on insufficient sidewalk width and worn out paving, 
which cause people to walk uneasily and leave the sidewalk for the carriageway, with high safety risk, or even to renounce to pedestrian mobility at all. As to pedestrian safety, there are no universally valid rules, especially when high flows of vehicles and pedestrians are concerned. Russo et al. [3], using databases of recorded road accidents, have identified a set of indicators for the variables of probability, vulnerability and exposition to casualties, defining also separate risk functions for each kind of hazard, in order to assess risk levels both locally and globally. All the factors that influence the accident rate were analyzed using the Safety Reviews [4]. This are check lists for road safety, that have been used to analyze problems, define objectives, identify critical points, find solutions and programme proper actions, in order to make urban intersections more accessible to road users with various degrees of disability.

\section{Study area}

Via Ruggero Settimo is a straight road in the 8th district of the Township of Palermo, connecting the two most important squares of the city, namely piazza Giuseppe Verdi, which surrounds the Teatro Massimo, the city opera house, and piazza Ruggero Settimo, at the centre of which is the Teatro Politeama, the house of the Sicilian Philharmonic Orchestra. This road is actually a tract of a longer road, opened in 1782 to connect the walled town to the several summer residencies and estates of the local aristocracy, scattered in the "Piana dei Colli", a flat area north of the old town. Via Ruggero Settimo extends for about $350 \mathrm{~m}$, with a $10 \mathrm{~m}$, on average, wide carriageway and it has 5 intersections open to vehicular traffic. The road hosts numerous shops and activities, and it is regarded as the most exclusive shopping area of the city. Owing to the high pedestrian flow, the road is closed to vehicular traffic on Sundays. Since 2001, a total of 18 road accidents involving pedestrians have been reported.

\section{Techniques to assess the quality and safety of pedestrian routes}

A complete analysis of the factors leading to pleasant and safe transfers on foot has been made possible by the use of GIS technology together with a defined set of indicators for pedestrian safety. For this purpose, a geo-database of the road accidents involving pedestrians that had been reported since 2001 in the city of Palermo was built. This analysis, on a wide time range, has allowed an identification of the most dangerous intersections along via Ruggero Settimo. The history of casualties has indicated proper and safe behaviours, which can be the base for future studies on road safety, especially in places and contexts where accidents repeat with similarities over the time. The analysis that has been carried out, is the starting point for the development of a new methodology to assess the quality and safety of pedestrian routes, resulting in the systematic identification of situations of highest risk along any given urban route. The next step has been the definition of a set of indicators for pedestrian safety, valid through a wide range of circumstances and able to point out the hidden hazards 
that the non-motorized road users have to face on their route. The hazards along urban roads are mainly linked to the promiscuity of the traffic components, in addition to the strong interactions between road users and the presence of conflict points. Locating critical points, both for safety and pleasantness, along pedestrian routes, is the final objective of the Safety Pedestrian Indicators. Each indicator has been obtained as a combination of its related indexes. Indexes have been classified according to an assigned weight, varying in the integer range from 1 to 4: the higher the weight, the greater the relevance of the index in the pedestrian mobility context. In addition, conditions described by a given index can be regarded as acceptable or unacceptable depending on the index weight like in the mentioned classification (tab. 1).

Table 1: Weights assigned to indexes.

\begin{tabular}{c|c|c|c}
\hline \multirow{2}{*}{ Indicator } & \multirow{2}{*}{ Index } & \multicolumn{2}{|c}{ Conditions } \\
\cline { 2 - 4 } & & Acceptable & Unacceptable \\
\hline \multirow{2}{*}{ SAI } & SLOS & 1 & 4 \\
\cline { 2 - 4 } & PW & 1 & 3 \\
\hline \multirow{2}{*}{ PCSI } & CLOS & 1 & 4 \\
\cline { 2 - 4 } & DV & 1 & 4 \\
\hline \multirow{3}{*}{ PRPI } & SF & 1 & 2 \\
\cline { 2 - 4 } & SL & 1 & 2 \\
\cline { 2 - 4 } & PTA & 1 & 3 \\
\hline
\end{tabular}

The main aspect to be assessed is the "Sidewalk Accessibility Indicator" (SAI). The SAI accounts for the presence of physical obstacles, such as sidewalk width and maintenance conditions. Specifically, the indexes relative to this indicator are the Sidewalk LOS, obtained for the study area through the procedure proposed by the HCM (fig. 1), and the sidewalk wear condition. As can be seen in Table 1, if the sidewalk level of service is rated either A, B or C, the SLOS index is defined as acceptable, and thus is assigned a weight of 1 $\left(\mathrm{SLOS}_{1}\right)$. Levels of service rated $\mathrm{D}, \mathrm{E}$, or $\mathrm{F}$ are defined as unacceptable because of insufficient sidewalk width or presence of physical obstacles effecting the pedestrian mobility comfort. In the case study presented, according to the classification shown in Table 1, the SLOS index is assigned a weight of 4 $\left(\mathrm{SLOS}_{4}\right)$ meaning that, relatively to the context described, the risk for pedestrian safety is rated as the highest. In fact, in this particular case, people tend to walk on the carriageway when the sidewalk is crowded, increasing the chances of being involved in an accident.

The pavement wear condition (PW) has been subjected to the same analysis, and a weight of 3 has been assigned to the relative index $\left(\mathrm{PW}_{3}\right)$, where pavement conditions reduce the pedestrian comfort. Once defined the SAI indexes, the Sidewalk Accessibility Indicator of each sidewalk is obtained by combining the SLOS and PW indexes as shown in Table 2. 


\begin{tabular}{|c|c|c|c|c|c|c|c|c|}
\hline 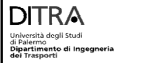 & \multicolumn{8}{|c|}{$\begin{array}{l}\text { Pedestrian Safety Indicators: } \\
\text { Study elements about road crossings }\end{array}$} \\
\hline & \multicolumn{8}{|c|}{ L.o.S. Sidewalk } \\
\hline & 10 & $L_{\text {sot }}[\mathrm{m}]$ & $L_{i}[\mathrm{~m}]$ & $L_{u}[m]$ & $a_{15}$ & $\begin{array}{c}Q_{\text {pad }} \\
[\text { ped/(min } \mathrm{m})]\end{array}$ & \multicolumn{2}{|c|}{ LOS } \\
\hline & 11 & 2.7 & 1.6 & 1.1 & 391 & 23.70 & \multicolumn{2}{|c|}{ c } \\
\hline & 21 & 2.7 & 1.3 & 1.4 & 463 & 21.57 & \multicolumn{2}{|c|}{$B$} \\
\hline & 31 & 5.5 & 1.5 & 4 & 469 & 7.82 & \multicolumn{2}{|c|}{$A$} \\
\hline & 41 & 2.5 & 1.7 & 0.8 & 478 & 39.83 & \multicolumn{2}{|c|}{ D } \\
\hline 12 & 51 & 2.5 & 0.8 & 1.7 & 495 & 19.41 & \multicolumn{2}{|c|}{ B } \\
\hline & 61 & 3 & 0.8 & 2.2 & 476 & 14.42 & \multicolumn{2}{|c|}{ A } \\
\hline & 71 & 3 & 1.4 & 1.6 & 481 & 20.04 & \multicolumn{2}{|c|}{$B$} \\
\hline & 81 & 3 & 1 & 2 & 522 & 17.40 & \multicolumn{2}{|c|}{ B } \\
\hline & 10 & $L_{\text {ot }}[\mathrm{m}]$ & $L_{i}[\mathrm{~m}]$ & $L_{1}[\mathrm{~m}]$ & $Q_{15}$ & $\underset{[p e d /(\min \mathrm{m}) 1}{Q_{\text {pas }}}$ & \multicolumn{2}{|c|}{ LOS } \\
\hline & $1 \mathrm{r}$ & 2.7 & 0.9 & 1.8 & 403 & 14.93 & \multicolumn{2}{|c|}{ A } \\
\hline & $2 r$ & 2.7 & 1.3 & 1.4 & 413 & 19.67 & \multicolumn{2}{|c|}{ B } \\
\hline & $3 r$ & 2.7 & 1.3 & 1.4 & 485 & 23.10 & \multicolumn{2}{|c|}{ c } \\
\hline & $4 r$ & 5.5 & 1.5 & 4 & 493 & 8.22 & \multicolumn{2}{|c|}{ A } \\
\hline & $5 r$ & 5.5 & 1.5 & 4 & 510 & 8.50 & \multicolumn{2}{|c|}{ A } \\
\hline & $6 r$ & 3 & 0.8 & 2.2 & 533 & 16.15 & \multicolumn{2}{|c|}{$B$} \\
\hline & $7 \mathrm{r}$ & 2.5 & 0.9 & 1.6 & 546 & 22.75 & \multicolumn{2}{|c|}{ B } \\
\hline & \multicolumn{8}{|c|}{ L.O.S. Pedestrian Crossing } \\
\hline & \multicolumn{8}{|c|}{ Signalized Intersections } \\
\hline & 10 & \multicolumn{2}{|c|}{ "C" cycle length [s] } & \multicolumn{3}{|c|}{$\begin{array}{l}\text { "g" effective green time (for } \\
\text { pedestrians) [s] }\end{array}$} & $d_{p}[s]$ & LOS \\
\hline & a & \multicolumn{2}{|c|}{102.00} & \multicolumn{3}{|c|}{51.00} & 12.75 & B \\
\hline & c & \multicolumn{2}{|c|}{102.00} & \multicolumn{3}{|c|}{51.00} & 12.75 & B \\
\hline \multirow{6}{*}{$\begin{array}{l}\text { Prof, Salvetore Amoroso } \\
\text { Eng. Luigi Caruso }\end{array}$} & d & \multicolumn{2}{|c|}{102.00} & \multicolumn{3}{|c|}{51.00} & 12.75 & B \\
\hline & $f$ & & & & 51.0 & & 12.75 & $\mathrm{~B}$ \\
\hline & & & Unsig & nalize & Inter & sections & & \\
\hline & 10 & $L[\mathrm{~m}]$ & $\mathrm{s}_{\mathrm{p}}[\mathrm{m} / \mathrm{s}]$ & $T_{s}[s]$ & $T_{c}[s]$ & $\mathrm{v}$ [vehic/s] & $d_{p}[s]$ & LOS \\
\hline & $\mathrm{b}$ & 9.00 & 1.40 & 2.00 & 8.43 & 0.29 & 28.51 & D \\
\hline & e & 9.00 & 1.40 & 2.00 & 8.43 & 0.28 & 26.00 & D \\
\hline
\end{tabular}

Figure 1: $\quad$ Sidewalk and pedestrian crossing L.O.S. evaluation.

Table 2: $\quad$ Sidewalk Accessibility Indicator evaluation.

\begin{tabular}{c|c|c}
\hline & SLOS $_{1}$ & SLOS $_{4}$ \\
\hline $\mathrm{PW}_{1}$ & $\mathbf{S A I}_{1}$ & $\mathbf{S A I}_{3}$ \\
\hline $\mathrm{PW}_{3}$ & $\mathbf{S A I}_{2}$ & $\mathbf{S A I}_{4}$ \\
\hline
\end{tabular}

Table 3: $\quad$ Pedestrian crossing safety indicator evaluation.

\begin{tabular}{c|c|c}
\hline & $\mathrm{CLOS}_{1}$ & $\mathrm{CLOS}_{4}$ \\
\hline $\mathrm{DV}_{1}$ & $\mathbf{P C S I}_{1}$ & $\mathbf{P C S I}_{3}$ \\
\hline $\mathrm{DV}_{4}$ & $\mathbf{P C S I}_{2}$ & $\mathbf{P C S I}_{4}$ \\
\hline
\end{tabular}

The Pedestrian Crossing Safety Indicator (PCSI) is obtained as a function of:

- level of service perceived (CLOS) by pedestrians when they cross the road both at signalized and unsignalized intersections;

- drivers' visibility (DV) of crossing pedestrians, considering possible sight obstructions (parked cars, trees, road signs, etc.) (tab. 3).

The last indicator to be considered is the Pedestrian Route Pleasantness Indicator (PRPI). The pedestrian route attractiveness can be evaluated by an assessment of street furniture (SF), street lighting (SL), and public transit accessibility (PTA), if present (fig. 2). 


\begin{tabular}{|c|c|c|}
\hline & $\mathrm{PTA}_{1}$ & $\mathrm{PTA}_{3}$ \\
\hline $\mathrm{SF}_{1}$ & PRPI* ${ }_{1}$ & PRPI ${ }_{2}$ \\
\hline $\mathrm{SF}_{2}$ & PRPI ${ }_{1}$ & PRPI $_{3}$ \\
\hline & $\mathrm{SL}_{1}$ & $\mathrm{SL}_{2}$ \\
\hline PRPI* $_{1}$ & $\mathrm{PRPI}_{1}$ & $\mathrm{PRPI}_{2}$ \\
\hline $\mathrm{PRPI}_{2}$ & PRPI $_{1}$ & $\mathrm{PRPI}_{2}$ \\
\hline $\mathrm{PRPI}_{3}{ }_{3}$ & $\mathrm{PRPI}_{2}$ & $\mathrm{PRPI}_{3}$ \\
\hline
\end{tabular}

Figure 2: $\quad$ Pedestrian Route Pleasantness Indicator evaluation.

$$
\mathrm{CSR}=\mathrm{SAI} * \mathrm{PCSI} * \mathrm{PRPI}
$$

\begin{tabular}{|c|c|c|c|c|}
\hline & $\mathrm{SAI}_{1}$ & $\mathrm{SAI}_{2}$ & $\mathrm{SAI}_{3}$ & $\mathrm{SAI}_{4}$ \\
\hline $\mathrm{PRPI}_{1}$ & $\operatorname{CSR}^{*}{ }_{1}$ & $\operatorname{CSR}^{*}{ }_{1}$ & $\mathrm{CSR}_{3}^{*}$ & $\operatorname{CSR}_{4}^{*}$ \\
\hline $\mathrm{PRPI}_{2}$ & $\mathrm{CSR}^{*}{ }_{1}$ & $\mathrm{CSR}_{2}^{*}$ & $\mathrm{CSR}_{3}^{*}$ & $\mathrm{CSR}^{*}{ }_{4}$ \\
\hline $\mathrm{PRPI}_{3}$ & $\mathrm{CSR}_{2}{ }_{2}$ & $\mathrm{CSR}_{2}^{*}$ & $\mathrm{CSR}_{4}^{*}$ & $\mathrm{CSR}_{4}^{*}$ \\
\hline
\end{tabular}

\begin{tabular}{|c|c|c|c|c|}
\hline & $\mathrm{PCSI}_{1}$ & $\mathrm{PCSI}_{2}$ & $\mathrm{PCSI}_{3}$ & $\mathrm{PCSI}_{4}$ \\
\hline $\mathrm{CSR}^{*}{ }_{1}$ & $\mathrm{CSR}_{1}$ & $\mathrm{CSR}_{1}$ & $\mathrm{CSR}_{2}$ & $\mathrm{CSR}_{3}$ \\
\hline $\mathrm{CSR}_{2}{ }_{2}$ & $\mathrm{CSR}_{1}$ & $\mathrm{CSR}_{2}$ & $\mathrm{CSR}_{3}$ & $\mathrm{CSR}_{4}$ \\
\hline $\mathrm{CSR}_{3}{ }_{3}$ & $\mathrm{CSR}_{2}$ & $\mathrm{CSR}_{3}$ & $\mathrm{CSR}_{3}$ & $\mathrm{CSR}_{4}$ \\
\hline $\mathrm{CSR}^{*}{ }_{4}$ & $\mathrm{CSR}_{3}$ & $\mathrm{CSR}_{4}$ & $\mathrm{CSR}_{4}$ & $\mathrm{CSR}_{4}$ \\
\hline
\end{tabular}

Figure 3: Critical Spot Rating evaluation.

Table 4: Hazard level rating evaluation.

\begin{tabular}{|c|c|c|c|c|}
\hline & $\mathrm{CSR}_{1}$ & $\mathrm{CSR}_{2}$ & $\mathrm{CSR}_{3}$ & $\mathrm{CSR}_{4}$ \\
\hline $\mathrm{ARR}_{1}$ & HLR $_{1}$ & $\mathrm{HLR}_{1}$ & $\mathrm{HLR}_{2}$ & $\mathrm{HLR}_{3}$ \\
\hline $\mathrm{ARR}_{2}$ & $\mathbf{H L R}_{\mathbf{1}}$ & $\mathbf{H L R}_{\mathbf{2}}$ & $\mathrm{HLR}_{3}$ & $\mathbf{H L R}_{4}$ \\
\hline $\mathrm{ARR}_{3}$ & $\mathrm{HLR}_{2}$ & $\mathrm{HLR}_{2}$ & $\mathrm{HLR}_{4}$ & $\mathrm{HLR}_{4}$ \\
\hline
\end{tabular}

The three previously defined indicators combined as shown in figure 3 define the Critical Spot Rating (CSR) by the following equation:

The Hazard Level Rating (HLR) of the studied road is determined as the product of the Critical Spot Rating and the Accident Risk Rating (ARR) (tab. 4). 
Table 5: Accident risk rating evaluation.

\begin{tabular}{l|l}
\hline $\mathrm{ARR}_{1}$ & Reported Accidents $=0$ \\
\hline $\mathrm{ARR}_{2}$ & Reported Accidents $=1$ \\
\hline $\mathrm{ARR}_{3}$ & Reported Accidents $\geq 2$ \\
\hline
\end{tabular}

The Accident Risk Rating is a function of the number of accidents reported in the study area, and as the other indicators, increases as the value of its index increases (tab. 5).

The Hazard Level Rating relative to the studied road is obtained by combining the Critical Spot Rating with the Accident Risk Rating. It's worth reminding the reader that the Hazard Level Rating is not meant as an absolute measure of the degree of danger but rather as a way to compare and classify different critical situations according to the reported casualties and pedestrian safety indicators. Thus, if a particular situation results in a low Hazard Level Rating, this doesn't imply low danger in absolute terms, but rather lower danger relatively to other situations, on an ordinal scale of priorities. There are four possible Hazard Level Ratings ranging from $\mathrm{HLR}_{1}$ to $\mathrm{HLR}_{4}$; a higher index means a higher level of danger. This determines an order of priority in taking measures to reduce risks along pedestrian routes, according first to the Hazard Level Rating, then to the Critical Spot Rating, and last to the Accident Risk Rating:

$$
\begin{aligned}
& 1^{\circ} \text { level }=\mathrm{HLR}_{4}\left(\mathrm{CRS}_{4}-\mathrm{ARR}_{3}\right) ; \\
& 2^{\circ} \text { level }=\mathrm{HLR}_{4}\left(\mathrm{CRS}_{4}-\mathrm{ARR}_{2}\right) ; \\
& 3^{\circ} \text { level }=\mathrm{HLR}_{4}\left(\mathrm{CRS}_{3}-\mathrm{ARR}_{3}\right) ; \\
& 4^{\circ} \text { level }=\mathrm{HLR}_{4}\left(\mathrm{CRS}_{4}-\mathrm{ARR}_{1}\right) ; \\
& 5^{\circ} \text { level }=\mathrm{HLR}_{4}\left(\mathrm{CRS}_{3}-\mathrm{ARR}_{2}\right) .
\end{aligned}
$$

The method proposed has been applied to via Ruggero Settimo, by dividing the road in to 9 macro tracts (Boxes) with similar characteristics (fig. 4). Then, for each box, the Hazard Level Rating has been determined and the procedure, relative findings and Critical Spot Ratings have been summarized on a table. Specific information relative to each box has been assembled and treated, using geomatic techniques in order to create the thematic maps shown in figure 5.

It should be noted that the SA indicator and the PCS indicator are global indicators since they account for both of the opposite sidewalks in the box, and have been determined by combining together the corresponding indicators of each single sidewalk, as shown in tables 6 and 7.

\section{Conclusions}

The method presented is a new assessment tool for pedestrian safety that aims to make walking a real mode of urban transport, alternative to the less sustainable ones, and not just a leisure and spare time activity. Pedestrian mobility quality 
and safety can be effectively assessed through the Pedestrian Safety Indicator, this will contribute to render walking in town more popular and more attractive for citizens. Too often narrow or inexistent sidewalks, poor public lighting, wide roads to cross and low public transit accessibility keep people away from

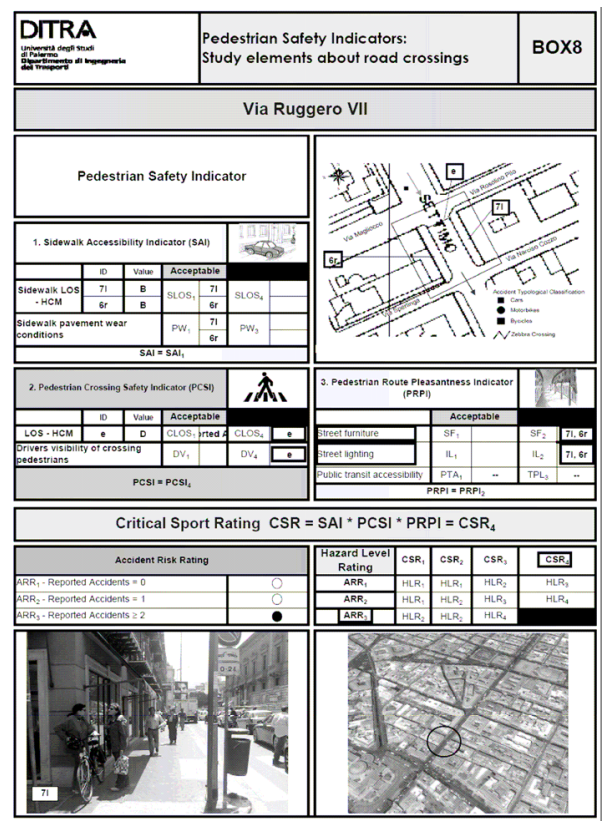

Figure 4: $\quad$ Example of Box.

Table 6: $\quad$ Sidewalk Accessibility Indicator evaluation.

\begin{tabular}{c|c|c|c|c}
\hline & $\mathrm{SAI}_{1}$ & $\mathrm{SAI}_{2}{ }_{2}$ & $\mathrm{SAI}_{3}$ & $\mathrm{SAI}_{4}{ }_{4}$ \\
\hline $\mathrm{SAI}^{\mathrm{L}}{ }_{1}$ & $\mathbf{S A I}_{1}$ & $\mathbf{S A I}_{1}$ & $\mathbf{S A I}_{\mathbf{2}}$ & $\mathbf{S A I}_{3}$ \\
\hline $\mathrm{SAI}_{2}{ }_{2}$ & $\mathbf{S A I}_{2}$ & $\mathbf{S A I}_{2}$ & $\mathbf{S A I}_{3}$ & $\mathbf{S A I}_{3}$ \\
\hline $\mathrm{SAI}_{3}{ }_{3}$ & $\mathbf{S A I}_{2}$ & $\mathbf{S A I}_{3}$ & $\mathbf{S A I}_{3}$ & $\mathbf{S A I}_{4}$ \\
\hline $\mathrm{SAI}_{4}{ }_{4}$ & $\mathbf{S A I}_{3}$ & $\mathbf{S A I}_{3}$ & $\mathbf{S A I}_{4}$ & $\mathbf{S A I}_{4}$ \\
\hline
\end{tabular}

Table 7: Sidewalk accessibility indicator evaluation.

\begin{tabular}{c|c|c|c|c}
\hline & PRPI $_{1}$ & PRPI $_{2}$ & PRPI $_{3}$ & PRPI $_{4}$ \\
\hline PRPI $^{\mathrm{L}}$ & PRPI $_{1}$ & PRPI $_{12}$ & PRPI $_{2}$ & PRPI $_{3}$ \\
\hline $\mathrm{PRPI}^{\mathrm{L}}{ }_{2}$ & PRPI $_{2}$ & PRPI $_{12}$ & PRPI $_{3}$ & PRPI $_{3}$ \\
\hline $\mathrm{PRPI}_{3}{ }_{3}$ & PRPI $_{2}$ & PRPI $_{3}$ & PRPI $_{3}$ & PRPI $_{4}$ \\
\hline $\mathrm{PRPI}^{\mathrm{L}}{ }_{4}$ & PRPI $_{3}$ & PRPI $_{3}$ & PRPI $_{4}$ & PRPI $_{4}$ \\
\hline
\end{tabular}



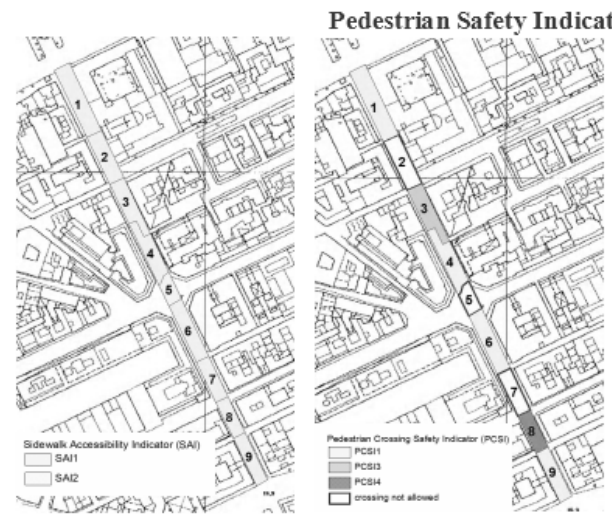
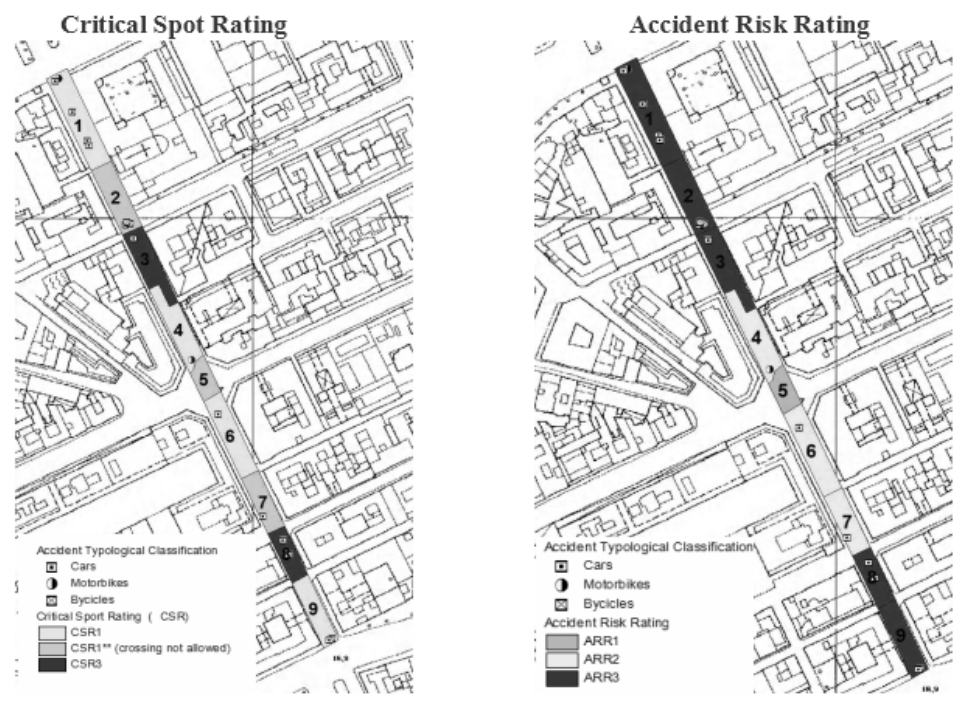

Accident Risk Rating

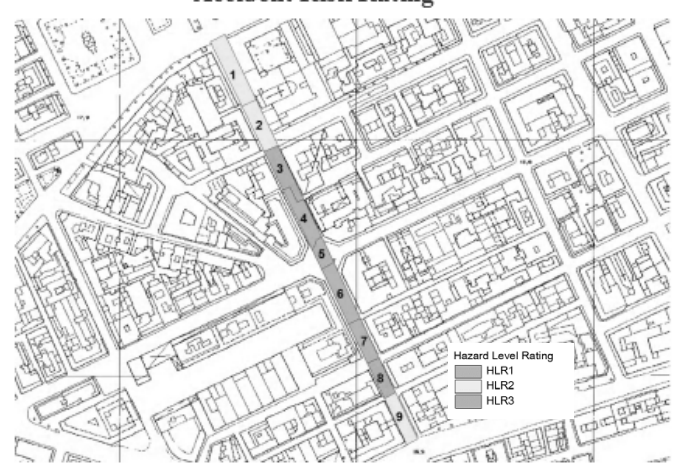

Figure 5: Thematic maps. 
walking in urban areas. The objective of this research is also the development of an algorithm, integrated with an open source GIS software, which may automatically implement the described method.

\section{References}

[1] Highway Capacity Manual, edition 2000;

[2] Di Mascio P., Morelli L., Un metodo di valutazione dello stato di servizio dei marciapiedi, XVI Convegno Nazionale S.I.I.V., Campus di Arcavacata di Rende (CS), 20-22 September 2006;

[3] Russo F., Vitetta A., Rindone C., Delfino G., Valutazione del rischio nelle infrastrutture stradali: approccio metodologico e sperimentazione per gli attraversamenti pedonali, XVI Convegno Nazionale S.I.I.V., Campus di Arcavacata di Rende (CS), 20-22 September 2006;

[4] Crisafulli M. C., Leopardi S., Safety Review per l'adeguamento degli incroci urbani in funzione delle esigenze degli utenti deboli, XVI Convegno Nazionale S.I.I.V., Campus di Arcavacata di Rende (CS), September 2006;

[5] Amoroso S., Caruso L., Percorsi pedonali e attraversamenti stradali: elementi per lo studio della qualità e della sicurezza, III Convegno Nazionale - La sicurezza sulle strade della città "Camminare in periferia", Lucca 2008;

[6] Cottrell W., Mu S., Development of new pedestrian crossing guidelines in Utah: Utah Department of Transportation Research and Development Division Department of Civil and Environmental Engineering - University of Utah Report No. UT-04.01 (2004);

[7] Bowman B. L., Vecellio R. L., Haynes D. W., Strategies for Increasing Bicycle and Pedestrian Safety and Use, Journal of Urban Planning and Development, Volume 120, Issue 3, (September 1994) pp. 105-114;

[8] AA.VV., Nonmotorized Transportation Around the World, Transportation Research Record $\mathrm{n}^{\circ}$ 1444, National Academy Press Washington, D.C. (1994);

[9] Archer J., Indicators for traffic safety assessment and prediction and their application in micro-simulation modelling: A study of urban and suburban intersections, Royal Institute of Technology, Stockholm, 2005. 